\title{
Impact Analysis of the 2011 Fukushima Nuclear Power Plant Accidents by Running Spectrum Analysis on Newspaper
}

\author{
Muneyoshi Numada and Kimiro Meguro \\ International Center for Urban Safety Engineering (ICUS), Institute of Industrial Science (IIS), University of Tokyo, Tokyo153-8505, \\ Japan
}

\begin{abstract}
Huge amount of digital data of the Great East Japan Earthquake is provided by the highly-developed digital data technology. But the method and technique for analysis of these huge digital data are not developed sufficiently. This paper proposes a running spectrum technique for text data and analyzing changes of disaster phase during the disaster management cycle. Impact analysis of the nuclear power plant accidents have been performed by using Fukushima Minpo newspaper for its verification. The result shows the dynamic characteristics of the nuclear power plant accidents. As the time interval B becomes longer, the analysis data is used from wide range period along with the smoothing effect. When observing different time intervals $\mathrm{B}$, fewer keywords have been ranked in the longer time intervals of B. The proposed technique is a powerful tool to analyze effectively the huge amount of digital data for the effective and efficient disaster response and management.
\end{abstract}

Key words: Impact analysis, Fukushima nuclear power plant accident, running spectrum analysis, newspaper.

\section{Introduction}

Huge amount of digital information related to the Great East Japan Earthquake has been published by newspapers, wire agencies and TV stations. The volume of information has exceeded that of past disasters because the tools by using to send out information have dramatically changed; Internet-based platforms are now widely used as popular sources for news updates. The contents covered include many different kinds of events and problems that were caused simultaneously by the earthquake. Reports on regional damage induced by the earthquake, tsunami and economic problems in the $^{1}$ Tokyo metropolitan area, Fukushima nuclear power plant accident and much other information spread out at the same time.

Cloud computing technology can evaluate more and

\footnotetext{
Corresponding author: Muneyoshi Numada, Ph. D, research field: disaster management. E-mail: numa@iis.u-tokyo.ac.jp.
}

more digital contents that produced and stored in the digital world. This new innovative environment and incorporating powerful delivery data system enable us to use information more easily for different purposes. However, the quality of data analysis technique in the disaster management field is far from enough. We need efficient means to distinguish important events out of the vast amount of information. Furthermore, we can get the movements within a certain time frame and know the changes occurring in the disaster management phase and so on.

Some algorithms in literature evaluation method suggest using association rules such as TF-IDF (term frequency-inverse document frequency) [1, 2], Z-score[3] and MIM (mutual information measure) [4]. The association rules and TF-IDF are based on term co-occurrence frequencies, while Z-score and MIM are based on term co-occurrence probabilities [5]. The characteristics of disaster-related-information change or shift in accordance with each disaster management 
cycle phase, which are namely damage mitigation, preparedness, prediction and early warning, damage assessment, emergency disaster response, recovery, and reconstruction/restoration.

When handling this kind of information with characteristics that depend on time-changing, it is necessary to make analysis within a certain time span. Therefore, we propose a dynamic analysis technique of literature with considerations on time series to offer proper and appropriate responses. This paper shows the overview of proposed techniques. News from the newspaper of Fukushima Minpo has been used for its verification. The proposed technique is a powerful tool to effectively analyze the huge amount of digital data, thereby responding to the upcoming society with growing volume of information.

\section{Running Spectrum Analysis of Text Data}

\subsection{Running Spectrum Analysis}

Running spectrum analysis is a method widely used in the seismic ground motion analysis for understanding the wave characteristics in time and frequency domain. It is an approach that shifts a time interval of analysis points to conduct analysis within a certain time frame. In our research, the target is further expanded to the literature field. It can be seen in Fig. 1 that moving-average method which is widely used to smooth short-term data fluctuations in time series is applied for dynamic analysis. The time interval B is defined as the calculating range for smoothing the data fluctuations.

\subsection{Flow of Text Data Running Spectrum Analysis}

Fig. 2 shows the flowchart diagram of running spectrum analysis on text data proposed in this research.

Firstly, Japanese Kanji letters, Katakana letters, numbers and alphabets are extracted from the documents separately as keywords. For this purpose, we have developed an EKP (extract-keyword-program). The EKP can extract each keyword individually and accurately. For example, "hinan" ("evacuation" in English) and "hinansya” ("evacuee” in English) are identified as different keywords within the same document. The EKP can also count the frequency of appearance within one certain day or all the days during the specified period. Users can freely reset the period depending on purposes.

Secondly, keywords are reviewed and analyzed. The weights of all extracted keywords are calculated respectively. Suggested algorithms for keyword analysis are: clustering, TF-IDF, LSI (latent semantic indexing), and co-occurrence. Our proposed system can choose the most suitable weighing approach according to the purposes and requirements of each user. In this paper, we have used TF-IDF in the time span B. TF-IDF is a statistical measurement method to evaluate the importance degree of a specified keyword in a document among a collection of numerous documents. The importance level is determined by the frequency and distribution within the collection of all documents [5].

To apply TF-IDF for the running spectrum analysis, TF-IDF value is calculated as:

$$
T F \cdot \operatorname{IDF}(t, j)=T F(t, j) \times \operatorname{IDF}(t, j)
$$

Where,

$$
\begin{gathered}
T F(t, j)=\frac{K j(t)}{K(t)} \\
\operatorname{IDF}(t, j)=\log \frac{T(t)}{T j(t)}
\end{gathered}
$$

where $K j(t)$ is number of occurrence of keyword $(j), K(t)$ is total number of occurrence keywords in the time interval $\mathrm{B}, T j(t)$ is number of literatures which includes keyword $(j)$ and $T(t)$ is total number of literatures in the time interval B.

Thirdly, after the evaluation of the importance of each keyword in certain time interval B, all keywords are ranked according to its weights.

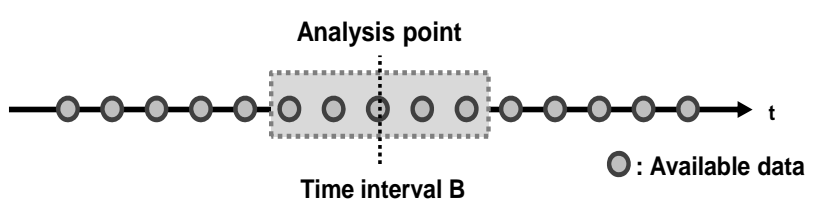

Fig. 1 Time interval $B$ of moving average method. 


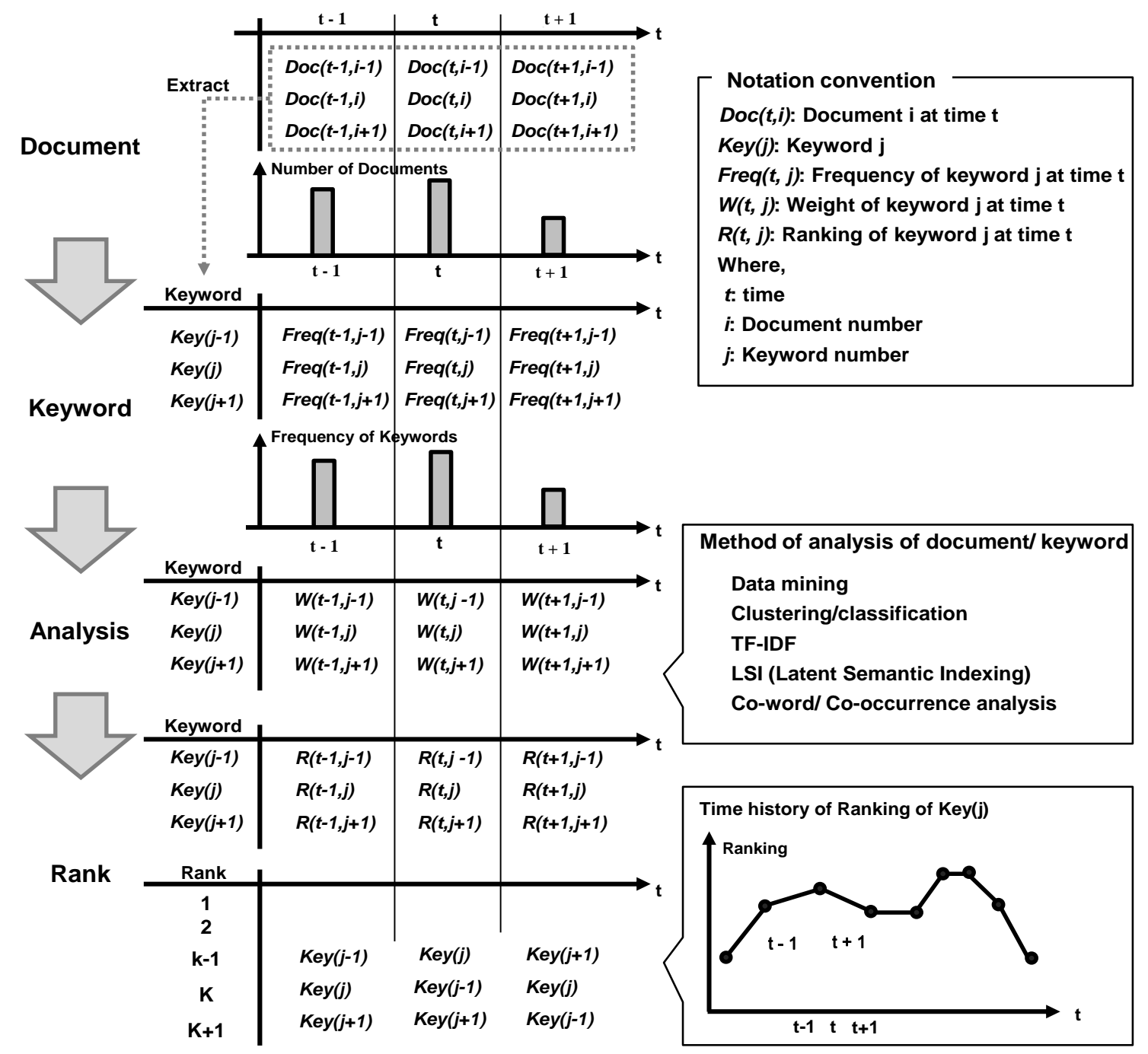

Fig. 2 Flowchart diagram for running spectrum technique.

\section{Case Study of Fukushima Minpo Newspaper}

\subsection{Newspaper data}

Fukushima Minpo is a local newspaper with circulation of 250 thousand copies per day and the largest in Fukushima Prefecture [6]. Newspaper repeatedly reports on nuclear power plant accidents as the company office is located near the site.

Some impact analysis of Fukushima nuclear disaster are carried out $[7,8]$, but a few researches analyze a newspaper to understand the time changing of the disaster.

Fig. 3 shows news report archives from March 2011 to May 2012, analyzing articles by the running spectrum approach described above.

Fig. 3 includes the reports about not only nuclear plant accidents but also earthquake, tsunami, and damages to analyze all impacts of this disaster.

\subsection{Extracting Keywords}

Fig. 4 shows the number of keyword items and its frequency. Total of 67,881 different keywords have been extracted. For example, frequency is shown as " 1 ” in 44,022 items ( $64.85 \%$ of the total), indicating that the keyword appears only one time. Most newspaper articles report the name, gender and age of those dead or injured, therefore the number of keywords with only one-time appearance equals the number of items. 


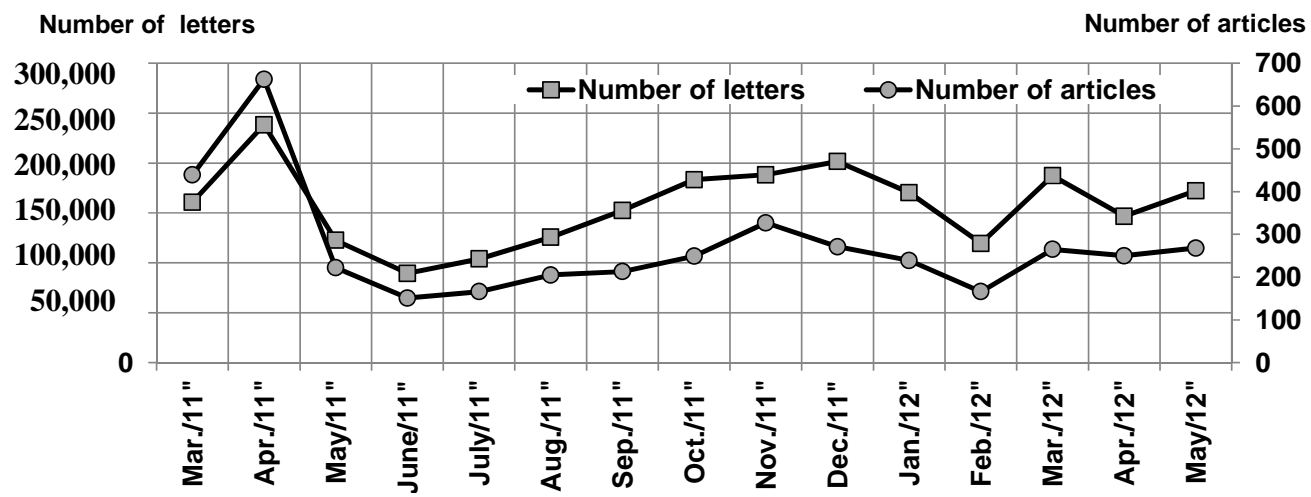

Fig. 3 Archives of Fukushima Minpo newspaper.

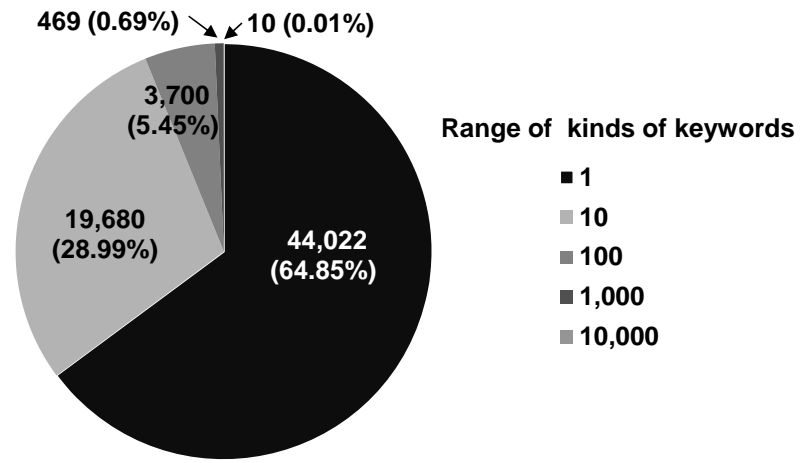

Fig. 4 The number of keyword items and its appearance within a certain range.

Fig. 5 represents keywords with high frequency. "Refuge" is listed as the most frequently used keyword with 1,696 appearances, followed by "residents" with 1,614 times over the period from March 2011 to May 2012. Because both tsunami and nuclear plant accidents induced the emergency evacuation and long-term evacuation to the people, refuge and residents are frequently used.

Keywords related to nuclear power accidents such as "decontamination", "nuclear power plant accident", "influence”, "radioactive material”, “children”, “dose of radiation” etc., are ranked high. In this study, one-letter words have been omitted because the keyword often has no meaning in itself and therefore should be interpreted within idioms, phrases and contexts.

\subsection{Results of Running Spectrum Analysis}

All keywords are given the rank respectively according to the weighting algorithm on daily or monthly level by proposed method. We get to understanding which keywords received attention at the time and tracing down the hottest keywords changing with the circumstances of the moment.

(1) Time-chart of the top ranked keywords: Table 1 shows the time chart of the top three ranked keywords having top ranking in a day in March 2011 as a sample period for $\mathrm{B}=3,7$ and 31 days respectively due to space limit of paper.

Taking a look at the B $=3$ cases, frequently used keywords in this emergency period immediately after the quake include "tsunami”, "evacuation”, “disaster victim” and "debris"; "Blanket” was another important word since the earthquake occurred during the winter season and blankets were strongly required by the evacuees.

On March 19th, due to worries about the spread of radiation from the nuclear power plant accident, the word "pregnant" was seen for the first time. On March 30th, "temporary home return" was ranked top. This was when the evacuees who had to leave their hometown for fear of radiation and were allowed to pay a brief visit home just to bring their valuables. The $\mathrm{B}=$ 7 case, which is similar to the $\mathrm{B}=3$ case, covers the time when the earthquake hit. Keywords described as emergency terms such as "tsunami”, "evacuation” and “debris” are seen. On March 16th and 17th, "pregnant” was ranked top indicating the serious concerns of radiation by pregnant women as in the $\mathrm{B}=7$ case. As for B = 31, "evacuation" and "refuge" were the most 

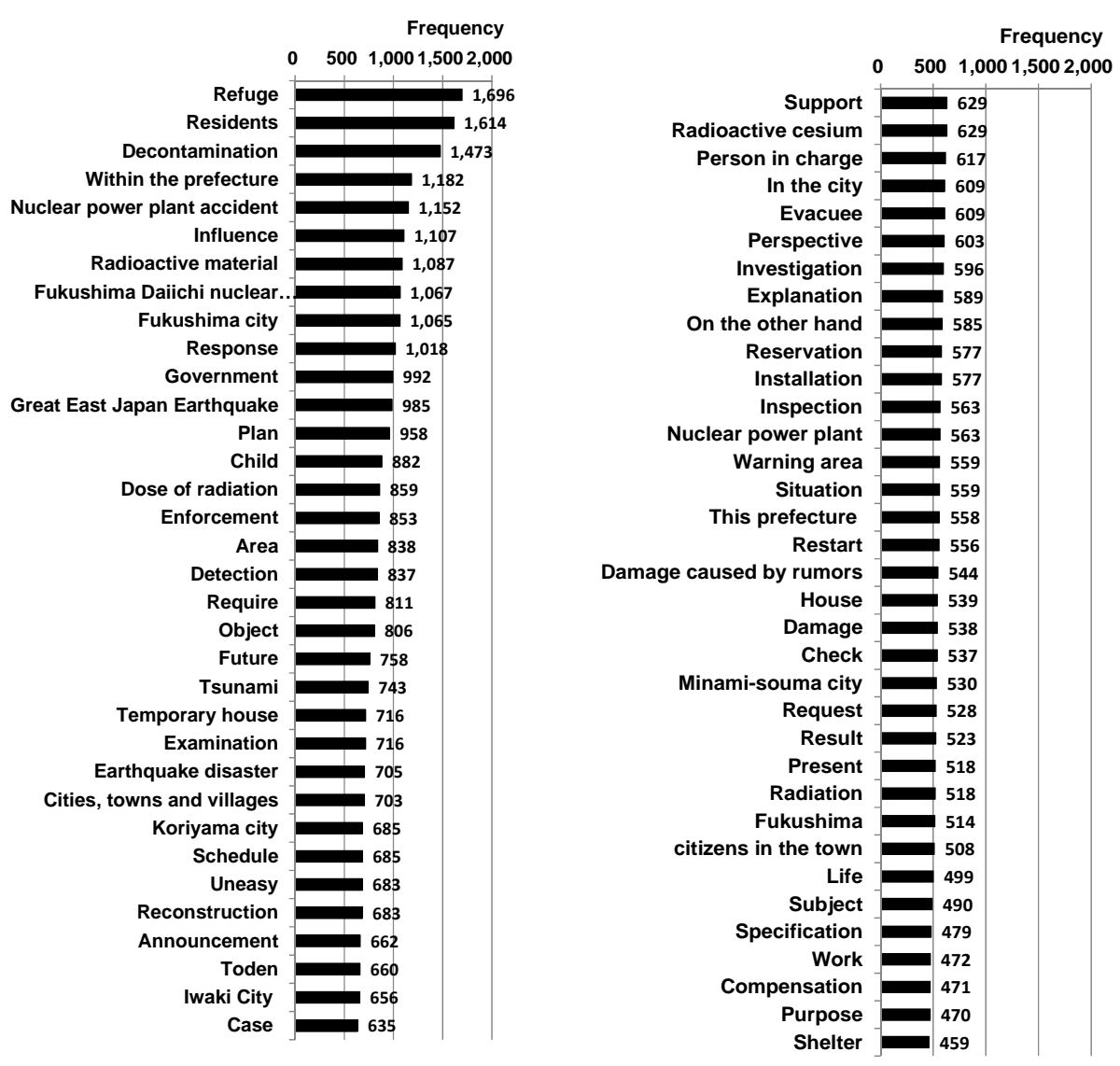

Fig. 5 List of Keywords and their appearance frequency (high frequency part).

used keywords for some days during emergency period. From March 22nd, “election” was ranked high because the nationwide local elections in April were also another issue of attention.

(2) Effect of different time interval B: Comparing the short and long time intervals in terms of " $\mathrm{B}$ ”, top ranked keywords change day by day in $\mathrm{B}=3$ (in which the target time interval days are shorter). On the other hand, some specific keywords, such as "evacuation”, “refugee”, “acceptance” and "election”, tend to be ranked higher in the longer time intervals. Therefore, because the time interval $B$ becomes longer, the analysis data is used from wide range period along with the smoothing effect.

The characteristics of the duration effect of time interval $B$ can be explained by how many kinds of keywords were ranked No. 1 at least once as shown in Fig. 6. When observing different time intervals $B=3,7$ and 31 days, fewer keywords have been ranked in the longer time intervals of $\mathrm{B}$. For example, the $\mathrm{B}=31$ case shows only 42 kinds of keywords ranked No. 1 while the B $=3$ case shows as many as 248 .

(3) Keywords ranked No. 1: Fig. 7 shows the keywords which were ranked No. 1, and how many times the keyword has reached the No. 1 position. The most frequently ranked as No. 1 include: “decontamination" with 15 times for B = 3 days, "sludge" with 22 times for B = 7 days and "planting" with 36 times for $\mathrm{B}=31$ days. From this result, we see that specific keywords were constantly listed high for the longer $B$ due to the effect of soothing.

Table 2 shows the time-history of keywords that remained No. 1 for a month. By reviewing this table, the timeline of events are observed. Unfortunately, only the top three are shown in this table due to the limitation of paper space even though many keywords remained in the No. 1 position for a month. Focusing on the $\mathrm{B}=31$ case, keywords of the months in 
Table 1 Time chart of ranking of keywords.

\begin{tabular}{|c|c|c|c|c|c|c|c|c|c|c|}
\hline & & \multicolumn{3}{|c|}{$B=3$} & \multicolumn{3}{|c|}{$B=7$} & \multicolumn{3}{|c|}{$B=31$} \\
\hline & & 1 & 2 & 3 & 1 & 2 & 3 & 1 & 2 & 3 \\
\hline \multirow{2}{*}{ 2011/3/11 } & Keyword & Fukushima city & Tsunami & Center & Tsunami & Evacuation & Disaster victim & Evacuation & Refuge & Response \\
\hline & TF-IDF & 0.015884 & 0.015884 & 0.015884 & 0.018549 & 0.017122 & 0.014268 & 0.011379 & 0.008302 & 0.007007 \\
\hline \multirow{2}{*}{ 2011/3/12 } & Keyword & Tsunami & Center & Evacuation & $\begin{array}{l}\text { Koriyama } \\
\text { city }\end{array}$ & Disaster victim & Evacuation & Evacuation & Refuge & Response \\
\hline & TF-IDF & 0.015694 & 0.015694 & 0.013079 & 0.012868 & 0.012433 & 0.010568 & 0.010424 & 0.007525 & 0.006362 \\
\hline \multirow[t]{2}{*}{ 2011/3/13 } & Keyword & Center & Generating & Offer & $\begin{array}{l}\text { Disaster } \\
\text { victim }\end{array}$ & Koriyama city & Evacuation & Evacuation & Refuge & Acceptance \\
\hline & TF-IDF & 0.007838 & 0.006532 & 0.006532 & 0.010186 & 0.007478 & 0.007099 & 0.009608 & 0.006706 & 0.005774 \\
\hline \multirow[t]{2}{*}{$2011 / 3 / 14$} & Keyword & Koriyama city & Disaster victim & $\begin{array}{l}\text { Suffering a } \\
\text { calamity }\end{array}$ & $\begin{array}{l}\text { Disaster } \\
\text { victim }\end{array}$ & Evacuation & Koriyama city & Evacuation & Refuge & Acceptance \\
\hline & TF-IDF & 0.013906 & 0.008126 & 0.005794 & 0.004954 & 0.004817 & 0.004578 & 0.008486 & 0.005925 & 0.005415 \\
\hline \multirow{2}{*}{ 2011/3/15 } & Keyword & Koriyama city & Debris & Business & Debris & Acceptance & Activity & Evacuation & Refuge & Acceptance \\
\hline & TF-IDF & 0.004075 & 0.003943 & 0.003943 & 0.003477 & 0.003367 & 0.003134 & 0.007612 & 0.005316 & 0.005158 \\
\hline \multirow{2}{*}{ 2011/3/16 } & Keyword & Business & Work & Part & Pregnant & Debris & Niigata prefecture & Evacuation & Acceptance & Refuge \\
\hline & TF-IDF & 0.003505 & 0.002804 & 0.002804 & 0.004234 & 0.003024 & 0.003024 & 0.006876 & 0.004736 & 0.004668 \\
\hline \multirow{2}{*}{ 2011/3/17 } & Keyword & Directions & Woman & Blanket & Pregnant & $\begin{array}{l}\text { Numerical } \\
\text { value }\end{array}$ & Detection & Evacuation & NPPA & Acceptance \\
\hline & TF-IDF & 0.002985 & 0.002985 & 0.002985 & 0.003366 & 0.002512 & 0.002476 & 0.005918 & 0.004135 & 0.004135 \\
\hline \multirow[t]{2}{*}{ 2011/3/18 } & Keyword & Pregnant & Citizen & $\begin{array}{l}\text { Niigata } \\
\text { prefecture }\end{array}$ & Last spring & Detection & Citizen & Evacuation & Acceptance & NPPA \\
\hline & TF-IDF & 0.004228 & 0.003020 & 0.003020 & 0.002930 & 0.002916 & 0.002287 & 0.005239 & 0.003820 & 0.003747 \\
\hline \multirow{2}{*}{ 2011/3/19 } & Keyword & Detection & Pregnant & Postponement & Last spring & Citizen & Detection & Evacuation & Acceptance & NPPA \\
\hline & TF-IDF & 0.003803 & 0.003803 & 0.003260 & 0.002767 & 0.002754 & 0.002046 & 0.005153 & 0.003757 & 0.003433 \\
\hline \multirow{2}{*}{$2011 / 3 / 20$} & Keyword & Last spring & Goods & Water supply & Citizen & Restart & Holding & Evacuation & Acceptance & NPPA \\
\hline & TF-IDF & 0.002857 & 0.002711 & 0.002449 & 0.002561 & 0.002292 & 0.002167 & 0.004497 & 0.003283 & 0.003125 \\
\hline \multirow[t]{2}{*}{ 2011/3/21 } & Keyword & Student & $\begin{array}{l}\text { Successful } \\
\text { applicant }\end{array}$ & Citizen & Citizen & Postponement & Holding & Evacuation & NPPA & Acceptance \\
\hline & TF-IDF & 0.004139 & 0.003726 & 0.003312 & 0.002103 & 0.002103 & 0.001896 & 0.003873 & 0.002961 & 0.002885 \\
\hline \multirow{2}{*}{ 2011/3/22 } & Keyword & Difficulty & Aizuwakamatsu & Holding & Holding & Last spring & Postponement & Evacuation & Election & NPPA \\
\hline & TF-IDF & 0.002421 & 0.002421 & 0.002118 & 0.001622 & 0.001622 & 0.001523 & 0.003244 & 0.002655 & 0.002600 \\
\hline \multirow{2}{*}{$2011 / 3 / 23$} & Keyword & Postponement & Holding & Life in refuge & Student & Holding & Last spring & Evacuation & Election & Acceptance \\
\hline & TF-IDF & 0.001976 & 0.001874 & 0.001606 & 0.001690 & 0.001598 & 0.001598 & 0.003221 & 0.002636 & 0.002519 \\
\hline
\end{tabular}




1

\begin{tabular}{lll}
\hline $2011 / 3 / 24$ & Keyword & Holding \\
& TF-IDF & 0.001555 \\
\hline
\end{tabular}

2011/3/25 Keyword Restoration

$2011 / 3 / 25$

TF-IDF $\quad 0.001899$

2011/3/26

Keyword Attendance

\begin{tabular}{lll} 
& TF-IDF & 0.003176 \\
\hline $2011 / 3 / 27$ & Keyword & $\begin{array}{l}\text { Radioactive } \\
\text { material } \\
\text { TF-IDF }\end{array}$ \\
0.004758 \\
\hline
\end{tabular}

2011/3/28 Keyword Acceptance

$$
\text { TF-IDF } \quad 0.006747
$$

$$
\mathrm{B}=3
$$
disaster

0.001333

Tokyo metropolitan 0.001625

Tomioka

0.002117

Tomioka

0.003569

Investigation 0.003680

$\begin{array}{llll}\text { 2011/3/29 } & \text { Keyword } & \text { Reservation } & \text { Fukushima } \\ & \text { TF-IDF } & 0.002896 & 0.002896\end{array}$

Keyword Temporary

Inside Shelter

$\mathrm{B}=7$

Life in refuge

0.001333

disaster

0.001625

Tokyo

metropolitan

0.002117 0.002826

TF-IDF 0.002826

2011/3/31 Keyword Victim

TF-IDF 0.005895

Sea water

0.003569

0.002681

Attendance Acceptance

0.003169

$0.002556 \quad 0.002283$

Accident

0.002556

Victim

Accident

Hotel

Victim

Accident

Victim Hotel

0.002711

Hotel

Restart

$\begin{array}{lll}0.004175 & 0.003578 & 0.003227 \\ \text { Victim } & \text { Hotel } & \begin{array}{l}\text { Japanese style } \\ \text { hotel }\end{array}\end{array}$

$\begin{array}{lll}0.004175 & 0.003578 & 0.003227 \\ \text { Victim } & \text { Hotel } & \begin{array}{l}\text { Japanese style } \\ \text { hotel }\end{array}\end{array}$

$\begin{array}{llll}0.003751 & 0.004514 & 0.003870 & 0.003490\end{array}$

\begin{tabular}{l} 
Radioactive \\
material \\
0.001886 \\
Japanese style \\
hotel \\
0.003156 \\
Japanese style \\
hotel \\
0.003227 \\
Japanese style \\
hotel \\
0.003490 \\
\hline
\end{tabular}

\begin{tabular}{llll} 
& \multicolumn{3}{c}{$\mathrm{B}=31$} \\
\hline & 2 & 3 \\
\hline Evacuation & Election & Acceptance \\
0.003200 & 0.002619 & 0.002503 \\
\hline Evacuation & Election & Acceptance \\
0.002723 & 0.002609 & 0.002493 \\
\hline Election & Acceptance & Detection \\
0.002573 & 0.002458 & 0.002356 \\
\hline Election & Acceptance & Detection \\
0.002539 & 0.002426 & 0.002325 \\
\hline Election & Acceptance & Detection \\
& 0.002553 & 0.002440 & 0.002338 \\
\hline Election & Acceptance & Postponement \\
& 0.002503 & 0.002392 & 0.002222 \\
\hline Election & Postponement & Acceptance \\
0.002442 & 0.002418 & 0.002334 \\
\hline
\end{tabular}




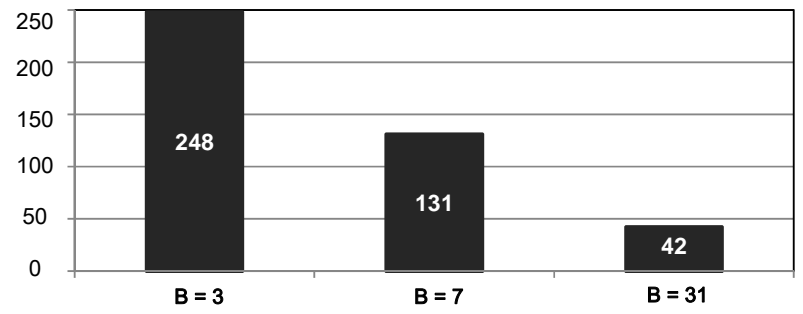

Fig. 6 Comparison of items of keywords ranked No. 1.

chronological order at the top are observed. "Evacuation" was the most important keyword in March 2011, followed by "disaster victim” (April), "temporary payment” (May), “sludge” (June), “specification” (July), “compensation” (August), "two points" (September), "forest for disaster mitigation" (October), “compost” (November), "rice” (December). Moving onto 2012, “rice” (January), "planting” (February), "center" (March) and "detection” (April and May). By following the top keywords, the outline and the stream of this complex disaster despite them intertwined problems and difficulties.

(4) Trend of each keyword: this system also analyzes the trend of specific keywords that a system user might take interest. For example, focusing on the top ranked keyword "planting" in Fig. 7c, the trend of its ranking is presented as seen in Fig. 8. The nuclear power plant accidents have given the impact to the planting of rice in the rice fields. The case $\mathrm{B}=3$ shows high discontinuity, while continuity is clearly shown in $\mathrm{B}=$ 31 due to the soothing effects. From around October 2011, the problems related to "planting" constantly emerge as shown in the $\mathrm{B}=31$ case.

\section{Conclusions}

We have proposed the running spectrum system for analyzing text data in the advanced society having digital data. The news reported by Fukushima Minpo newspaper is used for the verification of the technique and analyze of the impact of nuclear power plant accidents in Japan. The result shows the dynamic characteristics of the nuclear power plant accidents.

As time goes on, more digital information on natural disasters will become available. Then, the proposed technique serves efficiently and effectively to analyze huge amount of digital information, thus providing appropriate understanding of the impact of the nuclear power plant accidents.

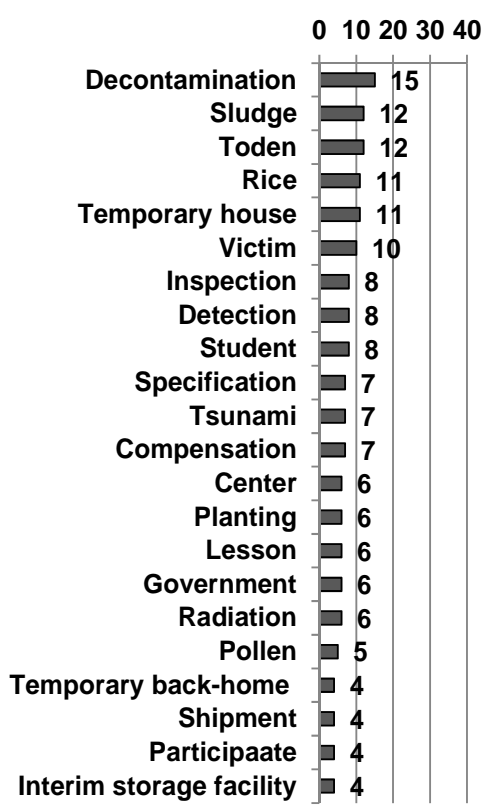

$\mathrm{B}=3$

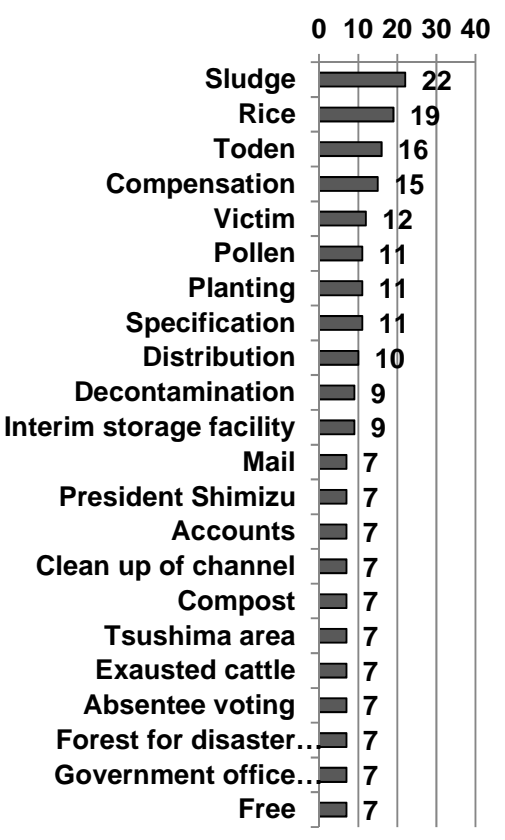

$\mathrm{B}=7$
010203040

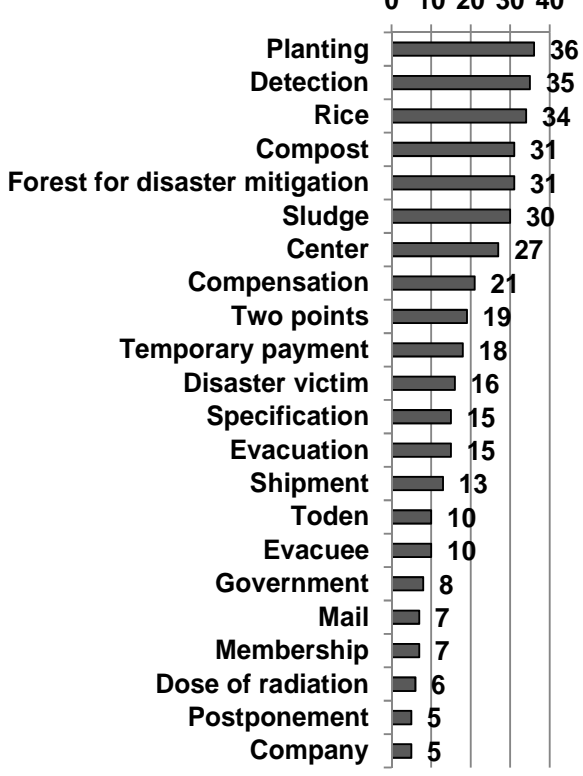

$\mathrm{B}=31$

Fig. 7 Keywords ranked as No. 1 and their frequency. 
on Newspaper

Table 2 Time-history of keywords that ranked as No. 1 with their frequency.

\begin{tabular}{|c|c|c|c|c|c|c|c|}
\hline & & $B=3$ & & $B=7$ & & $B=31$ & \\
\hline Year & Month & Keyword & $\begin{array}{l}\text { Number of } \\
\text { No. } 1\end{array}$ & Keyword & $\begin{array}{l}\text { Number of } \\
\text { No. } 1\end{array}$ & Keyword & $\begin{array}{l}\text { Number of } \\
\text { No. } 1\end{array}$ \\
\hline \multirow{30}{*}{2011} & \multirow{3}{*}{3} & Center & 3 & Last spring & 3 & Evacuation & 15 \\
\hline & & Pregnant & 2 & Student & 3 & Election & 5 \\
\hline & & Tsunami & 2 & Pregnant & 2 & Postponement & 1 \\
\hline & \multirow{3}{*}{4} & Student & 3 & President Shimizu & 7 & Disaster victim & 12 \\
\hline & & Move in & 3 & Danger & 4 & Evacuee & 5 \\
\hline & & Vegetables & 2 & Move in & 4 & Request & 5 \\
\hline & \multirow{3}{*}{5} & Japan Agriculture & 3 & Temporary payment & 5 & Temporary payment & 18 \\
\hline & & Temporary back-home & 3 & Toden & 5 & Government & 8 \\
\hline & & Temporary payment & 3 & Japan agriculture & 4 & Toden & 5 \\
\hline & \multirow{3}{*}{6} & Sludge & 3 & Sludge & 7 & Sludge & 19 \\
\hline & & Temporary house & 3 & Clean up of channel & 7 & Company & 5 \\
\hline & & Clean up of channel & 3 & Measurement & 5 & Temporary back-home & 2 \\
\hline & \multirow{3}{*}{7} & Specification & 4 & Specification & 9 & Specification & 15 \\
\hline & & Participate & 3 & Shipment & 4 & Shipment & 13 \\
\hline & & Ratio of adjustment & 3 & Beef cattle & 4 & Farmhouse & 3 \\
\hline & \multirow{3}{*}{8} & Student & 3 & Sludge & 3 & Compensation & 11 \\
\hline & & Specification & 3 & Compensation & 3 & Evacuee & 5 \\
\hline & & Pension for survivor & 2 & Announcement & 3 & Refuge & 5 \\
\hline & \multirow{3}{*}{9} & Reconciliation & 3 & Two points & 6 & Two points & 16 \\
\hline & & Prime minister Noda & 3 & Compensation & 5 & Compensation & 6 \\
\hline & & Mediation & 3 & Guardian & 4 & Temporary place & 4 \\
\hline & \multirow{3}{*}{10} & Rice & 3 & Rice & 7 & $\begin{array}{l}\text { Forest for disaster } \\
\text { mitigation }\end{array}$ & 23 \\
\hline & & Landslide & 3 & $\begin{array}{l}\text { Forest for disaster } \\
\text { mitigation }\end{array}$ & 7 & Two points & 3 \\
\hline & & $\begin{array}{l}\text { Forest for disaster } \\
\text { mitigation }\end{array}$ & 3 & Interim storage facility & 4 & Compensation & 3 \\
\hline & \multirow{3}{*}{11} & Wild boar & 3 & Compost & 7 & Compost & 22 \\
\hline & & Compost & 3 & Absentee voting & 7 & $\begin{array}{l}\text { Forest for disaster } \\
\text { mitigation }\end{array}$ & 8 \\
\hline & & Absentee voting & 3 & $\begin{array}{l}\text { Government office } \\
\text { building }\end{array}$ & 7 & 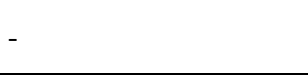 & - \\
\hline & \multirow{3}{*}{12} & Golf course & 3 & Tsushima area & 7 & Rice & 13 \\
\hline & & Sludge & 3 & Bark & 6 & Compost & 9 \\
\hline & & Recycle & 3 & Membership & 6 & Membership & 7 \\
\hline \multirow{15}{*}{2012} & \multirow{3}{*}{1} & Decontamination & 6 & Toden & 7 & Rice & 21 \\
\hline & & Hanami Yama mountain & 3 & Rice & 4 & Planting & 5 \\
\hline & & Government & 3 & Decontamination & 4 & Donation & 2 \\
\hline & \multirow{3}{*}{2} & Rice & 4 & Victim & 7 & Planting & 29 \\
\hline & & $\begin{array}{l}\text { Subsidy for } \\
\text { reconstruction }\end{array}$ & 3 & Pollen & 6 & - & - \\
\hline & & Planting & 3 & Subsidy for reconstruction & 5 & - & - \\
\hline & \multirow{3}{*}{3} & Free & 3 & Accounts & 7 & Center & 27 \\
\hline & & $\begin{array}{l}\text { Area where is difficult } \\
\text { to return }\end{array}$ & 3 & Distribution & 7 & Planting & 2 \\
\hline & & Distribution & 3 & Free & 7 & Iodine & 1 \\
\hline & \multirow{3}{*}{4} & Exhausted cattle & 3 & Mail & 7 & Detection & 12 \\
\hline & & Mail & 3 & Exhausted cattle & 7 & Mail & 7 \\
\hline & & Personnel & 3 & Pollen & 4 & Exhausted cattle & 5 \\
\hline & \multirow{3}{*}{5} & Cherry blossom & 3 & Sludge & 7 & Detection & 23 \\
\hline & & Sludge & 3 & Yanagisawa & 7 & Sludge & 8 \\
\hline & & Subsidy & 3 & Buying credit & 4 & - & - \\
\hline
\end{tabular}



on Newspaper

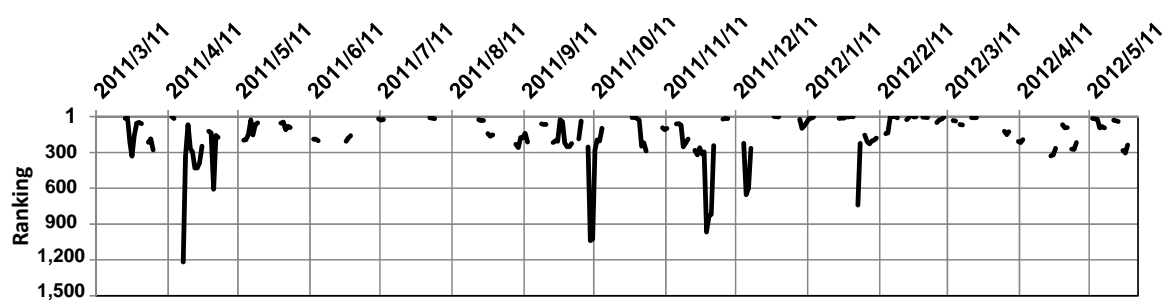

(a) $\mathrm{B}=3$ case

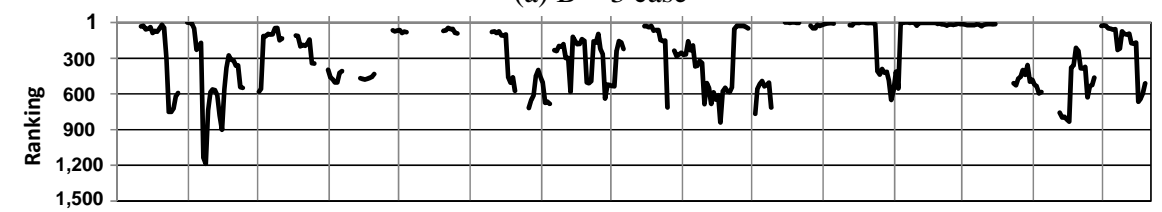

(b) $\mathrm{B}=7$ case

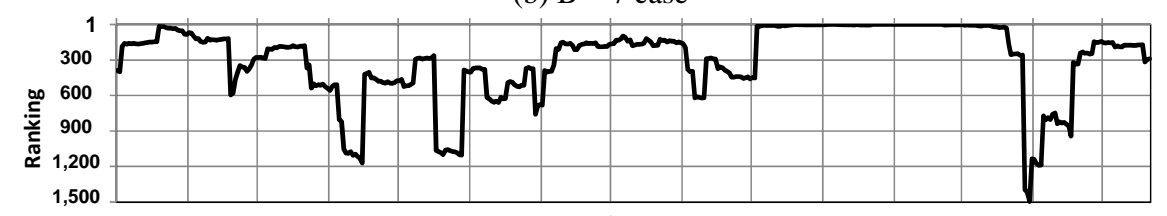

(c) $\mathrm{B}=31$ case

Fig. 8 Time history of ranking of "Planting".

\section{References}

[1] R.K. Lindsay, M.D. Gordon, Literature based discovery by lexical statistics, Journal of the American Society for Information Science and Technology 49 (1999) 674-685.

[2] P. Srinivasan, Generating hypotheses from MEDLINE, Journal of the American Society for Information Science and Technology 55 (2004) 396-413.

[3] M. Yetisgen-Yildiz, W. Pratt, Using statistical and knowledge-based approaches for literature based discovery, Journal of Biomedical Informatics 39 (2006) 600-611.

[4] J.D. Wren, Extending the mutual information measure to rank inferred literature relationship, BMC Bioinformatics 5 (2004) 145.
[5] Y.Y. Meliha, P. Wanda, A new evaluation methodology for literature-based discovery systems, Journal of Biomedical Informatics 42 (4) (2009) 633-643.

[6] Tohoku earthquake reports, Fukushima-Minpo Co., http://www.fukushimaminponews.com/ about.html (accessed Jun 28, 2012).

[7] S.K. Yeo, M.A. Cacciatore, D. Brossard, D.A. Scheufele, K. Runge, L.Y. Su, J. Kim, M. Xenos, E.A. Corley, Partisan amplification of risk: American perceptions of nuclear energy risk in the wake of the Fukushima Daiichi disaster, Energy Policy, 67 (2014) 727-736.

[8] H.A. Hassard, J.K.Y. Swee, M. Ghanem, H. Unesaki, Assessing the impact of the fukushima nuclear disaster on policy dynamics and the public sphere, Procedia Environmental Sciences, 17 (2013) 566-575. 